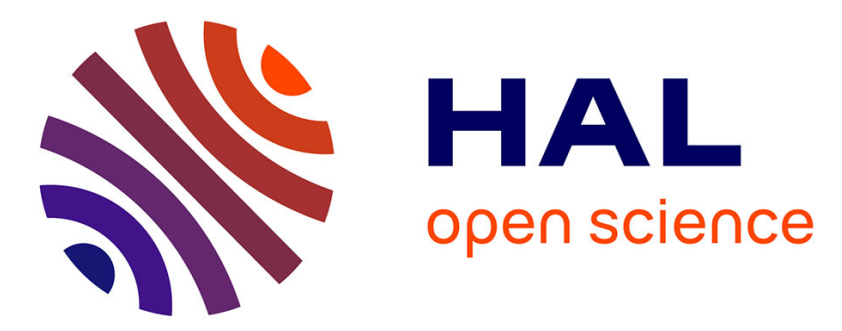

\title{
Measurements and modeling of PAH soot precursors in coflow ethylene/air laminar diffusion flames
}

\author{
A. Jerez, J.J. Cruz Villanueva, L.F. Figueira da Silva, R. Demarco, A. Fuentes
}

\section{To cite this version:}

A. Jerez, J.J. Cruz Villanueva, L.F. Figueira da Silva, R. Demarco, A. Fuentes. Measurements and modeling of PAH soot precursors in coflow ethylene/air laminar diffusion flames. Fuel, 2019, 236, pp.452-460. 10.1016/j.fuel.2018.09.047 . hal-03313664

\section{HAL Id: hal-03313664 \\ https://hal.science/hal-03313664}

Submitted on 19 Aug 2021

HAL is a multi-disciplinary open access archive for the deposit and dissemination of scientific research documents, whether they are published or not. The documents may come from teaching and research institutions in France or abroad, or from public or private research centers.
L'archive ouverte pluridisciplinaire HAL, est destinée au dépôt et à la diffusion de documents scientifiques de niveau recherche, publiés ou non, émanant des établissements d'enseignement et de recherche français ou étrangers, des laboratoires publics ou privés. 


\title{
Measurements and modeling of PAH soot precursors in coflow ethylene/air laminar diffusion flames
}

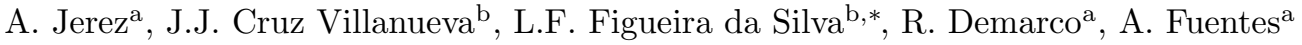 \\ ${ }^{a}$ Departamento de Industrias, Universidad Técnica Federico Santa María, Av. España 1680, \\ Valparaíso, Chile \\ ${ }^{b}$ Mechanical Engineering Department, Pontifícia Universidade Católica do Rio de Janeiro, Rio de \\ Janeiro, Brazil
}

\begin{abstract}
New experimental and numerical results of a laminar ethylene-air co-flow non-premixed flame are compared, in terms of soot volume fraction and temperature, and of polycyclic aromatic hydrocarbons $(\mathrm{PAH})$ distributions. Measurements involved UV-excited laser induced incandescence (properly calibrated), planar laser induced fluorescence (PLIF), and deconvoluted two-color pyrometry. In order to evidence soot and PAH, the comparison of prompt and delayed detection is carried out at four spectral detection wavelengths (340, 400, 450 and $550 \mathrm{~nm})$. Numerical results are obtained using a detailed gas-phase chemical kinetics mechanism considering 94 species and 719 reactions, and a sectional soot model, together with a statistical narrow band correlated K (SNBCK) wide band model to account for radiation. Computed PAH, grouped by their number of rings, is found to exhibit a good correlation with experimental PLIF results at different spectral detection wavelengths. In particular, it is shown that 340 and $400 \mathrm{~nm}$ fluorescence signals indicate the presence of one up to four-ringed computed PAH, whereas the interpretation of measurements at larger wavelengths is found to be elusive, due to soot signal overlap. Furthermore, an interplay between temperature decrease, soot volume fraction increase and radiative heat transfer distribution with increasing fuel flow rate is also demonstrated.
\end{abstract}

Keywords: Laminar flame, PAH, Laser Induced Fluorescence, Laser Induced Incandescence, Soot pyrometry 


\section{Introduction}

Combustion generated soot particles are known to have a detrimental effect on the environment [1]. Furthermore, recent studies have determined that cardiovascular mortality rates increase significantly upon augmented exposure to combustion-derived fine

5 particulates [2]. The ultra-fine nature of soot particles makes them capable of penetrating deeply into human organs and hence a serious health concern. The risks of arteriosclerosis, myocardial infarction, stroke and acute heart failure also increase upon exposure to air pollution and traffic. These consequences have been related both to the small particle size and to the aromatic nature of soot particles, becoming one of the most important problems to be solved nowadays. Soot particles are generated as a by-product of incomplete combustion of hydrocarbon fuels. Soot mainly consists of carbon and appears in the form of fractal aggregates formed by nearly spherical particles in the size range about 10 to $40 \mathrm{~nm}$. Soot is thus highly absorbing/emitting, making it an important global warming contributor, as well as an important heat transfer enhancer through thermal radiation, particularly in combustion industrial applications. Understanding and controlling soot particles formation is thus paramount to the design of novel engineering systems that are less harmful to the living organisms and might mitigate air pollution problems that mainly result from the use of fossil fuels.

This paper presents the results of a combined experimental and numerical study 20 of a laminar ethylene-air co-flow non-premixed flame. The goal is advance the basic understanding of the interplay between soot formation and polycyclic aromatic hydrocarbons $(\mathrm{PAH})$. This is effected by comparing UV-excited laser induced incandescence (LII) and planar laser induced fluorescence (PLIF) measurements with computational results obtained using a detailed gas-phase chemical kinetics mechanism and a sectional soot model. Indeed, both LII and PLIF techniques are spatially located in order to characterize soot and PAH [3, 4, respectively. In ethylene-air non-premixed co-flow flames, $\mathrm{PAH}$ are found to occur in an inner region, near the burner exit, and are surrounded by the soot region [5, 6, 7]. The PAH distribution along flames has been studied using different spectral detection bands [8]. Based on the fluorescence signal, its peaks shift

\footnotetext{
* Corresponding author:

Email address: luisfer@puc-rio.br (L.F. Figueira da Silva)
} 
30 to the infrared (IR) range as the PAH size increases [9]. The PAH fluorescence signal lifetime, of the order of tenths of nanoseconds, is smaller than that of soot incandescence, of the order of hundreds of nanoseconds. As consequence, a variable gate camera detection (prompt-delay) approach allows to discriminate PAH and soot by using a single UV-Visible laser excitation [8, 10, In such an approach the PAH fluorescence distribu35 tion is found to be the result of prompt (LIF+LII) signal subtracted by the delayed (LII) signal [11, 12, 13. However, since the different PAH fluorescence spectra overlap, the direct correspondence between such measured signals and a given PAH seems impossible without resorting to detailed flame modeling. The specific goal of the present study is thus to demonstrate which PLIF-PAH wavelength detection bands may correspond to a

40 given $\mathrm{PAH}$ range. This aim, which is achieved by comparing original experimental and modeling results, could open the door to apply such a correspondence to more complex turbulent flames [14, 15, 16.

In fact, to the best of the authors' knowledge, the majority of laminar non-premixed sooting flames studies involve the comparison of experimental data (soot volume frac-

45 tion, mean soot particle diameter) and models results with different level of sophistication. More extensive comparisons are also found that involve temperature, $\mathrm{C}_{2} \mathrm{H}_{2}$ and $\mathrm{OH}$ measurements with the corresponding simulated results [17, 18. The experimental/numerical results comparison of several non aromatic soot precursor species $\left(\mathrm{CH}_{4}\right.$, $\mathrm{C}_{2} \mathrm{H}_{6}, \mathrm{C}_{3} \mathrm{H}_{6}, \mathrm{C}_{2} \mathrm{H}_{2}$ ) distribution within non premixed flames has also been effected [19].

50 However, the detailed PAH model and measurement data comparison is seldom to be found, even if pure numerical predictions comparisons of different PAH sizes are often developed. For instance, the overall PAH trend with mixture composition has been used either as a baseline for qualitatively comparing with benzene (A1) computations in $\mathrm{C}_{2} \mathrm{H}_{4} / \mathrm{DME}$ mixtures [20] or to develop quantitative analysis [21].

55 Also, the computed PAH distribution of benzene or toluene doped flames have been analyzed in groups consisting of different ring numbers [22. These latter predictions exhibited significant differences with respect to large spectral band PLIF-PAH experimental data. Discrepancies have also been observed in more extensive numerical/experimental comparisons that involve several aromatic species (A3, A4, BGHIF) [23]. Therefore, the ${ }_{60}$ prediction of aromatic species in laminar sooting flames seems to be an open problem. 
This paper proceeds by presenting the experimental and numerical methodologies, as well as the technique used to compare the corresponding results. Then, comparisons between the computed soot volume fraction, temperature and PAH distributions are developed with respect to LII and PLIF-PAH data obtained at different detection wave-

${ }_{65}$ lengths. The computed results uncertainty with respect to the gas-phase chemical model are discussed by comparing the outcome of different kinetic mechanisms. Finally, the main conclusions and suggestions for future investigations are given.

\section{Experimental and Modeling Methodologies}

\subsection{Experimental Methodology}

The experiments are performed using a Gülder burner [24, which is commonly used to study soot formation in laminar and axisymmetrical non-premixed flames [25, 26, 27. This burner is composed of a $11 \mathrm{~mm}$ internal diameter stainless steel fuel injection tube, and of a coannular $100 \mathrm{~mm}$ internal diameter air flow duct. Two mass flow meters are used, Alicat Scientific MC-500SCCM-D/5M and MCH-100SLPM-D/5M, for ethylene and air flows, respectively, with a $1.8 \%$ maximum reading uncertainty for the fuel and $1.2 \%$ for the oxidizer flow (normal air). Different cases are studied in this work, in which the fuel flow rate injected is varied from $0.08 \mathrm{slpm}$ to $0.194 \mathrm{slpm}$. An air flow rate of $60 \mathrm{slpm}$ is kept constant for all experiments carried out. The simultaneous excitation of PLIF and LII is achieved with the $4^{\text {th }}$ harmonic $(266 \mathrm{~nm}$ ) of a Brilliant b (Quantel) Nd:YAG so laser [28, 5, 8, 6], operated at $10 \mathrm{~Hz}$ with $80 \mathrm{~mJ}$ nominal energy. A dichroic mirror filters the second harmonic $(532 \mathrm{~nm}$ ) residual component. An energy monitor (LaVision) is used to evaluate pulse energy variations, in order to reject results produced by laser energy fluctuations larger than a standard deviation. The laser beam is transformed into a thin planar sheet of $0.25 \times 25 \mathrm{~mm}^{2}$, using two pairs of lenses. The first two spherical lenses, ${ }_{85}$ with $f=-80 \mathrm{~mm}$ and $100 \mathrm{~mm}$, converge the beam to the desired thickness and the second pair of cylindrical lenses, $f=-50 \mathrm{~mm}$ and $150 \mathrm{~mm}$, vertically expand the source beam in order to obtain two-dimensional cross section in the measurement volume of the reaction zone, thus illuminating a plane at the center of the flame. The laser fluence curve measured for the studied flames indicate that the plateau region, i.e., the region where the LII signal is independent of the laser fluence, is found above $0.08 \mathrm{~J} / \mathrm{cm}^{2}$, which is the 
value adopted here. The images are captured using an intensifier (La Vision Intensified Relay Optics), with a P43 photo-sensor, equipped with a Nikon Rayfact PF10545MFUV lens and coupled to a CCD camera (Imager Intense, LaVision) with 12 bit dynamic range, a high resolution of $1376 \times 1040$ pixel, positioned orthogonal to laser sheet. The resulting spatial resolution is $26 \mathrm{px} / \mathrm{mm}$. The DaVis 8.1 software is used to control the trigger signal of laser and camera. Following previous studies 29] different interference filters centered at the wavelengths of 340, 400, 450 and 550 with $12.5 \mathrm{~nm}$ FWHM and $90 \%$ transmissivity are used in order to perform the flame spectral characterization. Note that LII signals are captured only at $400 \mathrm{~nm}(12.5 \mathrm{~nm}$ FWHM) in order to minimize noise and maximize the signal. Delayed detection with respect to laser pulse, $\geq 50 \mathrm{~ns}$, avoids the PAH fluorescence signal and is considered to represent soot incandescence only. Thus, a single camera gate of $20 \mathrm{~ns}$ and two distinct detection times $0 \mathrm{~ns}$ (prompt) and $50 \mathrm{~ns}$ (delay) are used to distinguish between the LIF and LII signals 30. One hundred single-shot images are used to obtain the average fields. Note that the adopted experimental technique may lead to nano-organic carbon (NOC) materia contributing to the measured fluorescence signals, which is not accounted for here. Determining the contribution level of NOC to the LIF signal is not straightforward and has been object of debates in recent literature [31, 32, 3, particularly because the detailed spectral of PAH and NOC data is still absent. In this sense we adopt the hypothesis that fluorescence signals are related mainly to $\mathrm{PAH}$ and, furthermore, that it is not possible to provide an estimate of the NOC emission in the LIF signal captured.

In order to obtain soot volume fraction values $\left(f_{s}\right)$ the LII results calibration is performed by laser extinction measurements [33, 30. A continuous $532 \mathrm{~nm}$ diode laser beam (LaVision model DPSS-0,5W-CW) is used with two energy monitors (LaVision, V.9) located before the flame and after the beam attenuation. The flame luminosity is rejected by a laser line filter $(532 \mathrm{~nm})$ placed in front of the second energy monitor. An iris is used to select a $4 \mathrm{~mm}$ diameter beam central region with $35.5 \mathrm{~mW}$, measured with Gentec Solo UP19K-15S. With the aim of obtaining a $330 \mu \mathrm{m}$ spatial resolution, the first pair of lenses described above is used. A constant non dimensional extinction coefficient of 4.51 is considered for the experimental diagnostic techniques [34]. Applying a typical error propagation equation [35] the corresponding soot volume fraction uncertainty is 
estimated to be $30 \%$, mostly due to soot refraction index uncertainties. In contrast, the largest standard deviation of the fluorescence signal is $15 \%$. Soot temperature measurements are achieved by using deconvoluted two-color pyrometry technique [27] with 530 and $900 \mathrm{~nm}$ (10 nm FWHM) inferential filters, together with the same CCD camera and lenses used for PLIF and LII. Camera images are corrected for the CCD quantum efficiency at these wavelengths. The line-of-sight emission measurements are Abel-inverted using an onion-peeling technique with a Tikhonov regularization [36, 37, 27. A similar analysis is conducted to estimate the uncertainties [38, leading to a maximum uncertainty of $16 \%$, which corresponds to $290 \mathrm{~K}$ at high soot temperatures.

\subsection{Numerical Model}

The CoFlame code [39] has been adapted to simulate the flames studied experimentally. CoFlame is a CFD code which solves the coupled transport equations of mass, momentum, energy, gas phase chemical species, soot aggregates number density and soot primary particles number. The coupled chemical solution uses the DLR kinetic mechanism, consisting of 94 species and 719 reactions [40, 17. This mechanism has been used successfully in studies involving soot production in flames fueled with C1-C2 hydrocarbons [17, 39. It includes the pyrolysis and oxidation of $\mathrm{C}_{1}$ and $\mathrm{C}_{2}$ species, linear hydrocarbons up to $\mathrm{C}_{6}$ species, the formation of benzene and further reactions leading to heavy PAHs, as well as the oxidation pathways of the aromatic species. The DLR mechanism was selected because its ability to predict up to 5 aromatic rings, species employed in the soot production model used. Such mechanism performance has been assessed for premixed and counterflow flames against experimental data [40, 41, however this assessment is yet to be done in co-flow diffusion flames. Carrying out simulations with a different mechanism would also imply the need to change the soot model. Despite of this, simulations results with the ABF mechanism [42, which are also discussed below, allow to evidence the possible discrepancies on the PAH concentration predictions. Carrying out a full benchmark of the PAH concentration prediction of a target flame from the literature is out of the scope of this study, though. The radiative source term in the energy transport equation is determined by the discrete ordinates method coupled to a statistical narrow-band-correlated K (SNBCK)-based wide-band model, considering the radiative properties of $\mathrm{CO}, \mathrm{CO}_{2}, \mathrm{H}_{2} \mathrm{O}$ and soot 43 . 
The fixed sectional soot model adopted in this study has been described and used in previous studies [44, 45, 46, 39]. The soot model consists of 35 discrete sections, following and simple way, albeit arbitrary. Since LIF spectral data for the different considered PAH does not seem to be available at the $266 \mathrm{~nm}$ excitation wavelength, a simple unweighted 
Table 1: Ring specification and PAH species considered in the analysis. Based on DLR kinetic mechanism 40].

\begin{tabular}{ll} 
Group & Species \\
\hline 1-Ring & $\mathrm{A} 1, \mathrm{~A}_{1} \mathrm{C}_{2} \mathrm{H}, \mathrm{C}_{7} \mathrm{H}_{8}, \mathrm{~A}_{1} \mathrm{C}_{2} \mathrm{H}_{3}$ \\
2-Ring & INDENE, INDENYL, A2, $\mathrm{A}_{2} \mathrm{C}_{2} \mathrm{H}$ \\
3-Ring & $\mathrm{A} 3, \mathrm{~A} 2 \mathrm{R} 5, \mathrm{~A} 3 \mathrm{C}_{2} \mathrm{H}$ \\
4-Ring & $\mathrm{C}_{18} \mathrm{H}_{12}, \mathrm{BGHIF}, \mathrm{A} 4, \mathrm{~A} 4-$ \\
5-Ring & BAPHYR, BAPYR*S \\
\hline
\end{tabular}

summation of the species mass fraction is adopted. This implies that all grouped species are assumed to fluoresce in a similar band [50] with similar intensity, which is a strong hypothesis, but one that seems to lead to acceptable results, as will be seen below. This follows previous recommendations from Verhoeven et al. 22, that stemmed from PLIF measurements and numerical PAH mass fraction comparisons for a $\mathrm{CH}_{4} / \mathrm{N}_{2}$-air co-flow diffusion flame with different dopants. In that work the molar mass was used to group the different species, together with a kinetic mechanism with fewer heavy PAH species than that adopted in the present study. Weighted sums/models of increased complexity could be envisaged, so as to provide a more refined analysis of the most important PAH species. However, this would require the detailed knowledge of the PAH spectra at temperatures representative of the flame, which is only available for a limited set of chemical species, e.g. in reference [51].

Here the species are selected based on their molecular structure, from the list of the available species at the used DLR kinetic mechanism [40. Each species considered in this study is individualized in Tab. 1. Only the highest three orders of magnitude in terms of species concentration have been retained for each ring, disregarding the effect of lower species; with the exception of BAPYR*S which is four orders of magnitude lower than BAPHYR. These are indeed the only two 5-ring species available from the mechanism used.

It is worth noting that the comparisons between the predicted gas-phase 5-ring PAH and the experimental $550 \mathrm{~nm}$ PLIF are to be regarded with caution, due to the influence of the soot model. Here 5-ring PAH have been utilized as the transfer species between 
the gas-phase and the soot particle phase for the nucleation and condensation processes. Thus, there is a partitioning of 5-ring PAH between the two phases. The ratio of this partitioning could vary by one to two orders of magnitude depending on what type of model (irreversible or reversible) and model parameters (efficiencies) are utilized. A limited understanding exists of what ratio this partitioning should physically have, thus conclusions for PAH connected directly to the soot model are subject to caution. This could also be the case to all PAH, since some portion of these might be related to soot growth and therefore be present in the soot phase or the gas-phase. This is not captured by the soot model used, nor is there a clear physical understanding of what this portion should be. However, it may be speculated that for smaller PAH this portion is likely to be smaller due to lower binding energies [52, 53 .

\section{Results and Discussion}

In this section are compared the results obtained with the combined LII/LIF technique and those corresponding to the numerical modeling. First, the overall flame incandescence and fluorescence signal distribution is presented. Then, a more detailed comparison of the results axial evolution is given, with emphasis on the identification of computed fluorescence species link to experimentally measured fluorescence. Finally, the radial profiles of temperature, soot volume fraction and PAH fluorescence distribution are compared to their computed species counterparts.

\subsection{Overall Flame Structure}

Figure 1 presents the field comparisons between experimental and numerical results for a fuel flow rate of $100 \mathrm{~cm}^{3} / \mathrm{min}$. The fields of fluorescence signals have been normalized by its overall peak value at each detection wavelength. The normalized PLIF signal at different wavelengths is compared to computed fluorescence species grouped according to their number of rings. The PLIF signal at $340 \mathrm{~nm}$ wavelength is thus related to species from one up to three rings $(1 \mathrm{R}+2 \mathrm{R}+3 \mathrm{R})$ (see Fig. 1a), the $400 \mathrm{~nm}$ wavelength result is compared to the three and four ring species $(3 \mathrm{R}+4 \mathrm{R}$ ) (see Fig. 1b), the $450 \mathrm{~nm}$ and the $550 \mathrm{~nm}$ wavelength are compared to the five rings species (5R) (see Figs. $1 \mathrm{c}$ and $1 \mathrm{~d}$. respectively, and Tab. 1 for details). Figure 1 also includes the measured and numerically 
estimated soot volume fraction predictions for comparison, whereas the temperature fields are given in Fig. 1e. From this figure can be observed that numerical predictions are in accordance with the estimated experimental temperature, presenting a similar field and a peak temperature deviation of $73 \mathrm{~K}$ only. Is important to mention that below $z=1.2 \mathrm{~cm}$ soot is absent at the centerline, which precludes the temperature estimation.

Experimental results show that, by increasing the detection wavelength, the most intense fluorescence zone occurs higher above the burner. For $550 \mathrm{~nm}$ the most intense zone is found to occur at almost the same position as the intense LII zone, where the soot volume fraction is around $0.7 \mathrm{ppm}$, a finding that is not unlike the recently measured PAH concentrations for premixed flames [54. Above this soot volume fraction value the PLIF signal is shaded by the LII signals, and therefore has been omitted by the image treatment. Numerical results for the two smaller wavelengths (340 and $400 \mathrm{~nm}$ ) reproduce the experimental distribution observed, considering not only the inner flame wing, but also the flame centerline. This suggests that the smaller PAH species fluoresce the most at smaller wavelengths, in accordance with previous findings [50]. Concerning the 450 and $550 \mathrm{~nm}$, the simulations predict very limited effects over the wing of the flame, in disagreement with the observed PLIF measurements. For these wavelengths the most intense zone is computed higher above the burner also. These differences could be related to the limitations of the species available, and their reactions from the kinetic mechanism.

255 Comparing the soot volume fraction iso-lines, numerical predictions are in agreement with the experimental measurements Indeed, the general distribution is well reproduced, with a similar peak value and height at the wing of the flame. Difference at the peak value is of $0.062 \mathrm{ppm}$ only. At the centerline vicinity (see $0.7 \mathrm{ppm}$ iso-line), a larger discrepancy is observed. Numerically, this difference is related to the position of the predicted 5-ring species, which are the model soot precursors.

\subsection{Analysis along the Flame Centerline}

Figure 2 allows to examine in further detail the behavior at the flame centerline. One should note that the centerline is not expected to be the most chemically active region of the flame. Indeed, it could be preferable to analyze the results at a maximum temperature level, however, soot temperature could not be measured in regions where soot formation 

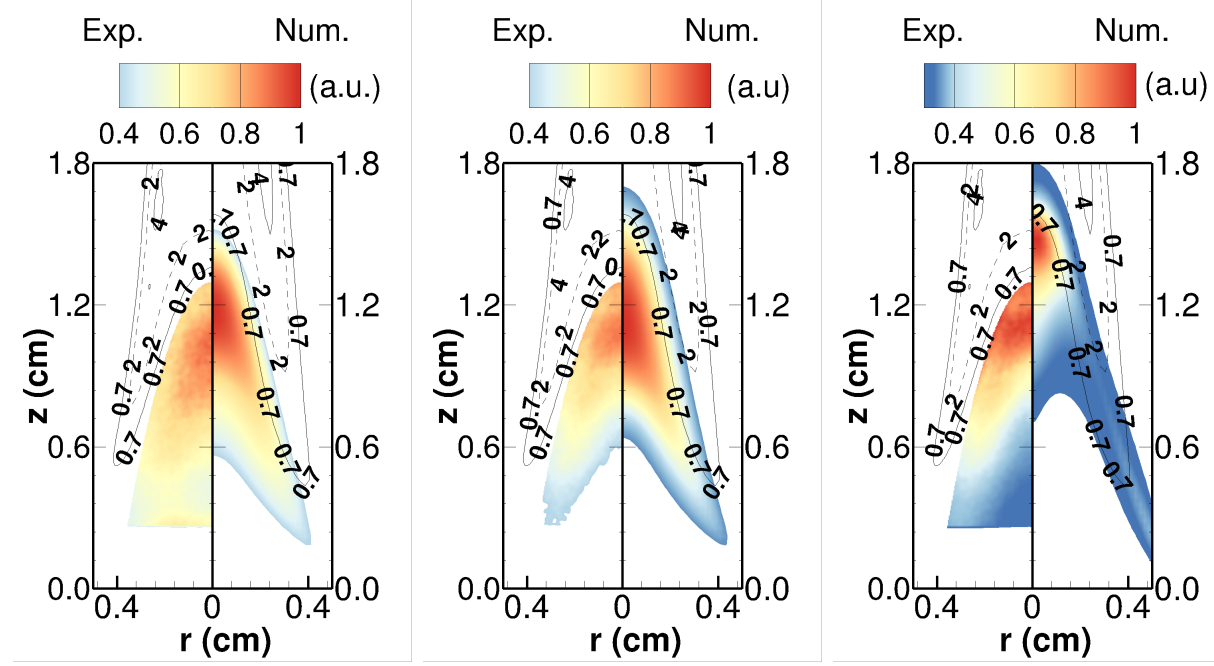

(a) PLIF $(340 \mathrm{~nm})-f_{\text {soot }}$

(b) PLIF $(400 \mathrm{~nm})-f_{\text {soot }}$
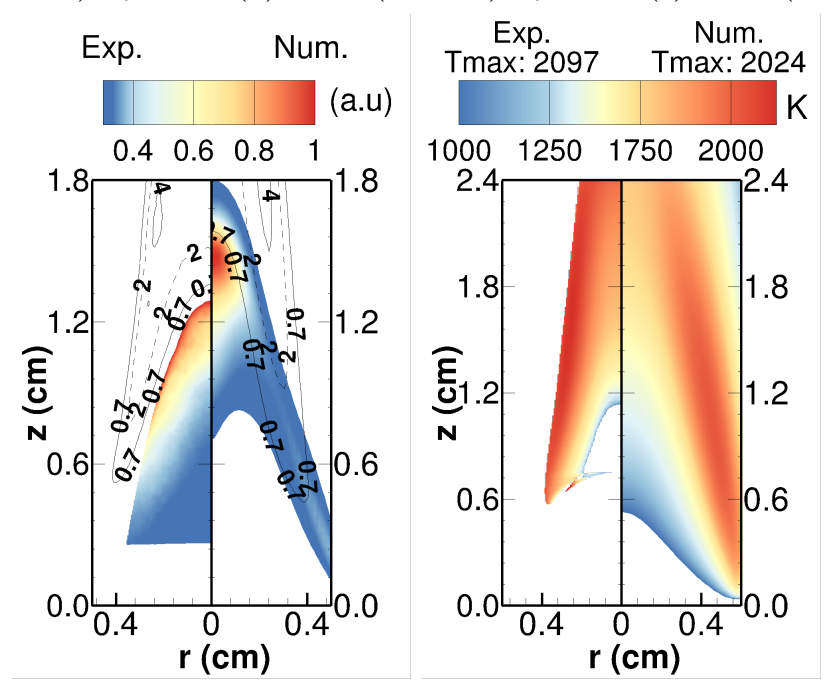

(d) PLIF $(550 \mathrm{~nm})-f_{\text {soot }}$

(e) Temperature

Figure 1: Normalized PLIF measurements obtained at different wavelengths (left) and computed fluorescence species estimates obtained from different PAH (right). $340 \mathrm{~nm}: 1 \mathrm{R}+2 \mathrm{R}+3 \mathrm{R}, 400 \mathrm{~nm}: 3 \mathrm{R}+4 \mathrm{R}$, 450 and $550 \mathrm{~nm}$ : 5R. Soot volume fraction measurements and numerical estimates are also presented in contour lines (in ppm) from (a) to (d). Measured soot and computed temperature distributions are presented in (e). Results presented are obtained for a fuel flow rate of $100 \mathrm{~cm}^{3} / \mathrm{min}$. 
is incipient. The centerline of the flame should thus provide a representative locus of comparison between the experimental and numerical results. In Fig. 2 the contribution of each PAH is given, grouped according to the number of rings in their structure. Each top graph presents the normalized mass fraction of each group of species, their addition (denoted as Num PAH and the corresponding wavelength), and the normalized PLIF measurements for comparison. Is important to note that experimental centerline profiles have been normalized by the overall peak value at each wavelength, which are deviated from the centerline, thus explaining that the peak does not reach 1. The PLIF signal and the numerical fluorescent species exhibit similar trends for the three wavelengths presented, even if a lesser variation may be seen for the measured results The bottom of the figure shows the normalized mass fraction of each species involved in the upper plot, which allows to observe the individual species contribution for the numerical fluorescence at each wavelength. More specifically, it can be observed that $\mathrm{A}_{1} \mathrm{C}_{2} \mathrm{H}$ is the one ring species that dominates, followed closely by A1. INDENE, on the other hand, is the most abundant two ring species, which also presents a peak much lower in the flame when compared to other species, pertaining to the one or two ring group. Contribution of INDENE is comparable in mass fraction to the $\mathrm{A}_{1} \mathrm{C}_{2} \mathrm{H}$ or the $\mathrm{A} 1$. $\mathrm{A} 3$ dominates the three rings species, (see Fig. 2a), whereas, for the four ring species, $\mathrm{C}_{18} \mathrm{H}_{12}$ is the species with higher computed mass fraction. This is the most abundant species among all the predicted PAH (see Fig. 2b). Finally, concerning the five ring species, BAPYR mass fraction is much larger than BAPHYR*S, as shown in Fig. 2c.

Further insight on the flame structure may be obtained by examining the numerical evolution along the flame center line of temperature, soot volume fraction and normalized PAH mass fraction, given in Fig. 3. The measured temperature uncertainty is of $16 \%(290 \mathrm{~K})$, and the modeled and experimental results discrepancy is of this order of magnitude. This good agreement is not observed for the soot volume fraction, which maximum measured value, $3.5 \mathrm{ppm}$, is under-predicted to be $1.5 \mathrm{ppm}$ at the flame axis. However, the position of the important increase observed in $f_{s}$ is correctly reproduced, indicating that soot production is effectively related to heavy PAHs, as it could be expected from the model adopted. In terms of the PAH estimates, close to the burner the 2 -ring species INDENYL dominates the $1 \mathrm{R}+2 \mathrm{R}+3 \mathrm{R}$ profile (Num $340 \mathrm{~nm}$ ). As the tem- 


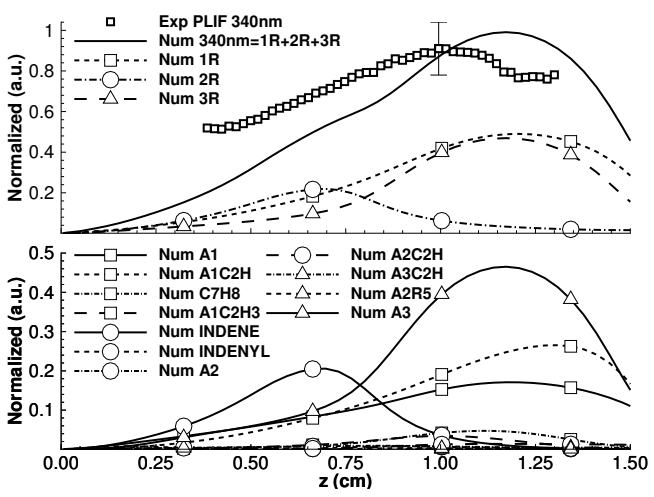

(a) PLIF $(340 \mathrm{~nm})$
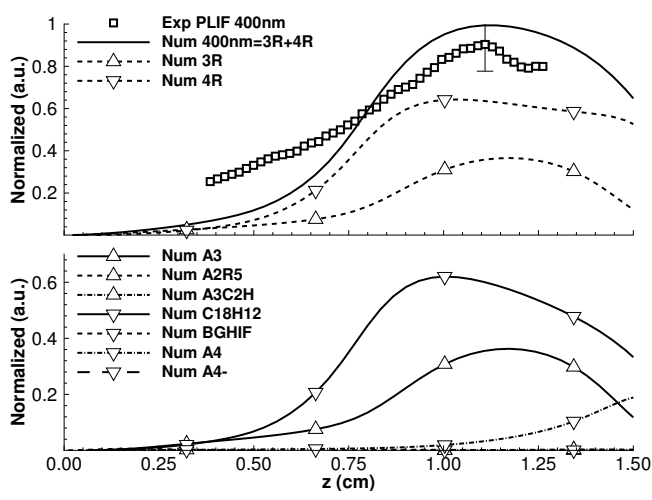

(b) PLIF $(400 \mathrm{~nm})$

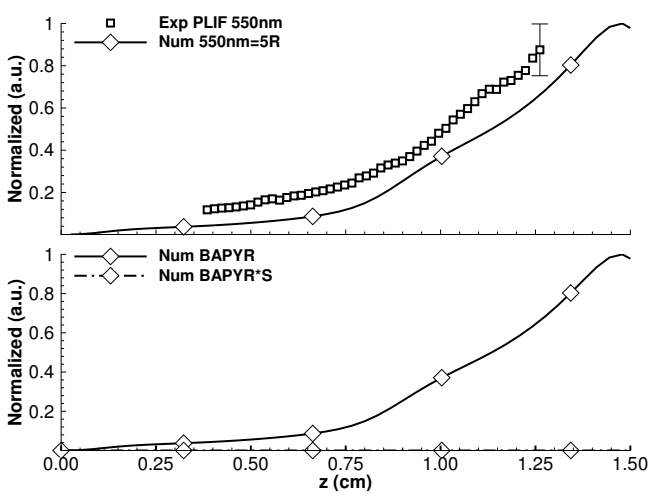

(c) PLIF $(550 \mathrm{~nm})$

Figure 2: Centerline evolution of the aromatic species grouped according to their number of rings for a fuel flow rate of $100 \mathrm{~cm}^{3} / \mathrm{min}$. Normalized PLIF measurements are also given at different detection wavelengths. 


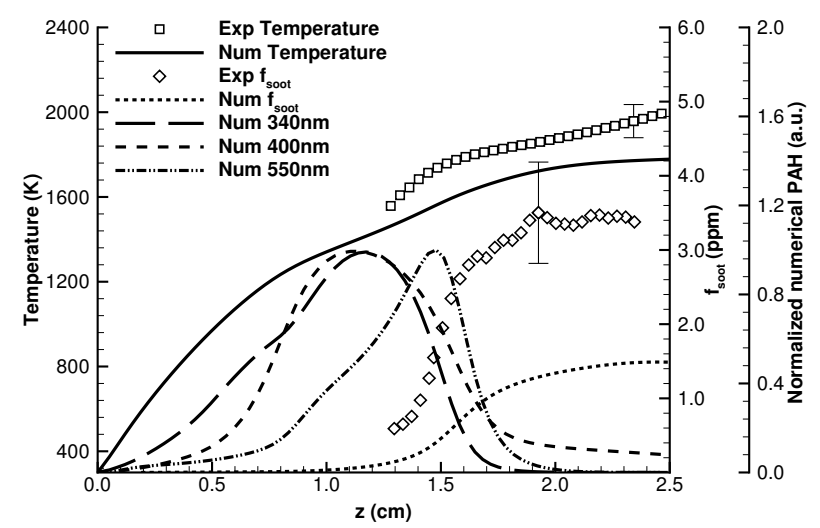

Figure 3: Evolution of temperature, soot volume fraction and mass fraction of main aromatic species at the flame centerline for a fuel flow rate of $100 \mathrm{~cm}^{3} / \mathrm{min}$.

perature increases A3 overtakes, dominating the 3-ring species over a height above the burner of $0.75 \mathrm{~cm}$. For the $3 \mathrm{R}+4 \mathrm{R}$ species (Num $400 \mathrm{~nm}$ ), this increase is weaker than that presented by $\mathrm{C}_{18} \mathrm{H}_{12}$, leading to a peak slightly closer the burner and wider than for the lighter species. The 5-ring species (Num $550 \mathrm{~nm}$ ), (mostly BAPHYR) exhibit a late increase, with respect to the lighter species, and a sharp decrease, yielding a narrower profile.

\subsection{Properties Radial Distribution}

Figure 4 presents the experimental and numerical radial profiles of temperature and soot volume fraction at identical normalized heights above the burner $\left(z / h_{f}\right)$ for three different fuel flow rates. At the lower height (Fig. 4a) is also given the measured PLIF at the two smaller detection wavelengths, together with the computed grouped PAH predictions for the intermediate fuel flow rate value, i.e, at $100 \mathrm{~cm}^{3} / \mathrm{min}$, so as not to overload the figure. One should note that a similar behavior is observed for the other fuel rates. Heavier PAH have not been included because of the limited agreement with the higher detection wavelengths. Experimental and numerical results are normalized by the experimental flame height, $h_{f}$, which are determined by the maximum vertical coordinate (z) where the flame emission at $431 \pm 5 \mathrm{~nm}$ is observed. This particular band is related to $\mathrm{CH}^{*}$ chemiluminescence self-emission. Experimental flame heights used for normalization are $2.39 \mathrm{~cm}$ for $80 \mathrm{sccm}, 3.16 \mathrm{~cm}$ for $100 \mathrm{sccm}$, and $4.72 \mathrm{~cm}$ for $140 \mathrm{sccm}$. Since the 


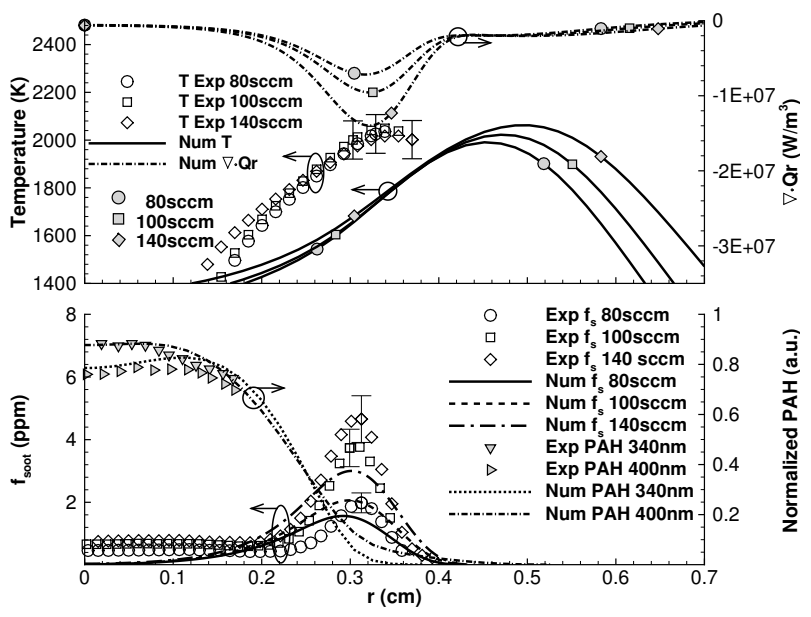

(a) $z / h_{f}=0.3$

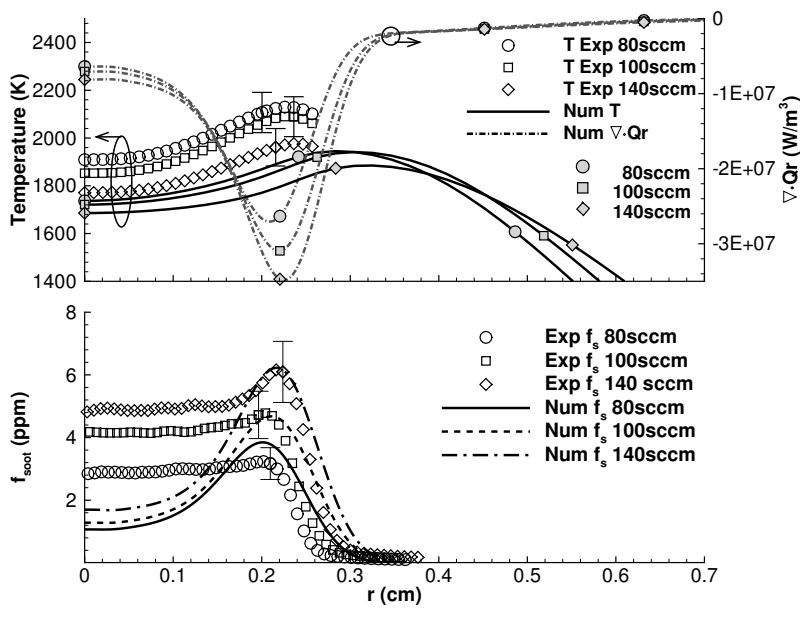

(b) $z / h_{f}=0.6$

Figure 4: Radial profiles of temperature, divergence of the radiative heat flux (top plot), soot volume fraction and PAH species (bottom plot) for three different fuel flow rates at two normalized flame heights. Symbols: experimental measurements; Lines: numerical predictions. 
temperature measurement technique relies on the soot spectral emission, temperature values are absent in oxidizer rich flame regions, i.e., beyond a certain radius. Figure 4 allows to observe that, even if the computed and measured temperature values present some disagreement in terms of magnitude and peak position, numerical simulations allows to understand the decreasing trend observed at the center axis by increasing the fuel flow rate. This behavior is somehow strange, since if more fuel is available for reaction an increase in the local temperature is expected. However, experimental results present the contrary. For the other side, experiments and simulations present an increase in the soot volume fraction by increasing the fuel flow rate. Such a trend is accompanied by an increase in the thermal radiation emitted by the flame, which can be observed as an (absolute) enhancement of the divergence of the radiative flux (see upper plots of Fig. 4) at the same position as the radial soot volume fraction peak This enhancement is thus responsible for lower flame temperatures observed both experimentally and numerically at the fuel rich regions. This is easily observable at $z / h_{f}=0.6$ (Fig $4 \mathrm{~b}$ ), but not very clear closer to the burner surface at $z / h_{f}=0.3$. At this height the soot volume fraction at the centerline vicinity is very small and the corresponding radiative heat flux is also very small. At this position it is also expected a lower temperature compared to higher heights. At the outer side of the flame, where the soot volume fraction decreases and all predicted heat fluxes are similar, the "normal" temperature trend is recovered, i.e., an increase in temperature by increasing the fuel flow rate. Therefore, soot emission is the responsible of the lower temperatures observed around the centerline by increasing the fuel flow rate.

Figure 4 allows to verify at both heights analyzed, and specifically at $z / h_{f}=0.6$, that predicted $f_{s}$ values at the outermost radii are in accordance with the experimental measurements obtained.. In particular, both the position and the values of the peaks are perfectly reproduced. However, as already stated above, at the centerline a discrepancy is observed. Numerical predictions present systematically lower quantities than the experimental measurements. Such discrepancies around the centerline could indicate that the soot model (in particular the condensation of PAH over the soot particles) and/or the soot precursor rates (BAPHYR and BAPYR*S) need some improvement. Note that previous modeling work demonstrates that the accurate prediction of centerline temper- 
ature is crucial for predicting both PAH and soot concentrations [55]. Thus, computed lower temperature at the centerline could also explain the underprediction of $f_{s}$ presented in Fig. 3 at the centerline. Finally, comparing the radial profiles of normalized PLIF signal and the computed fluorescence species should allow to observe that the agreement between these quantities is well within the $15 \%$ standard deviation of the PLIF results. This is an indication that the selected fluorescence observation wavelengths could be used as PAH species tracer according to their ring structure.

\section{Chemical Mechanism Uncertainty}

In order to assess if the procedure introduced in this study can be independent on the kinetic mechanism used, a comparison is carried out applying the classic mechanism of Appel, Bockhorn and Frenklach [42] (denoted as ABF). The ABF model has been selected both because of its historical importance, and of the large number of studies that have used it. This is carried out by comparing the results obtained with the DLR mechanism [40, both with and without coupling to the soot model, and those computed with the ABF mechanism [42], but without including a soot model. This is indeed necessary because the current soot model implementation requires 5 -ringed species, that are not present in the $\mathrm{ABF}$ chemical model, which is limited up to pyrene. Besides, it is interesting to assess if the disregarding of the soot calculation modifies the obtained results. Accordingly, Fig. 5 shows the temperature evolution along the centerline for these three computations.

It may be clearly noted that upstream to $z=1.5 \mathrm{~cm}$ the results discrepancies are negligible. Further downstream, the computation involving the DLR chemistry with the soot model exhibits, as it could be expected from the discussion above, a smaller temperature that when soot is not accounted for. The computations without the soot model using either the DLR or the ABF chemistry lead to nearly identical temperature results - the maximum discrepancy is about $50.7 \mathrm{~K}$ only, at $z \approx 2.5 \mathrm{~cm}$. This suggests that the chemical pathways associated to the combustion heat release are similar and, more importantly for the sake of the present argument, that the temperature influence on any PAH or soot model would be nearly identical, provided that the soot formation chemical pathways would also be similar. It may thus be argued that any discrepancies 


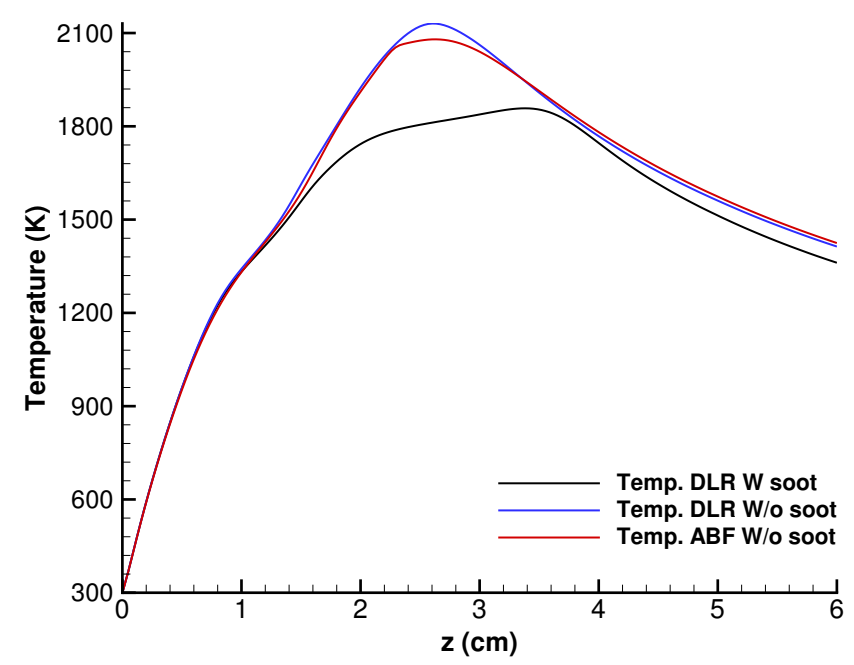

Figure 5: Comparison of computed centerline temperature evolution for different gas-phase chemical kinetic mechanism, accounting or not for soot formation.

on the computed PAH, at least in the non sooting region, stem from the PAH chemical pathways only. Therefore, comparing the predicted PAH distributions should allow to infer the overall uncertainties associated to the PAH gas phase chemistry. This is effected in Fig. 6, where are given the fields of lighter PAH, grouped as above.

This figure allows to verify that predictions using the DLR model are nearly identical, whether is considered the soot model or not, which indicates that the soot model consumption of larger PAH negligibly affects the lighter PAH (A1-A3) distribution. However, the results obtained when the ABF model is employed (without soot) lead to a longer light PAH plume when compared to the DLR results, in particular, the maximum PAH concentration is found to occur $5 \mathrm{~mm}$ downstream. Note that these PAH peak occur at 1.2 and $1.7 \mathrm{~cm}$, for the DLR and ABF mechanism respectively, i.e., in a location where a temperature is identical for these models. Even if a qualitative similarity between these results exist, such a discrepancy illustrates the uncertainty associated to these PAH chemical mechanisms, one which may be attributed to the chemical pathways only. It is beyond the scope of the present work to perform a chemical pathway analysis, though. Similar results are obtained by comparing the kinetic mechanisms at $400 \mathrm{~nm}$, grouping three and four-ring PAH species, presenting also a longer PAH plume when compared to 


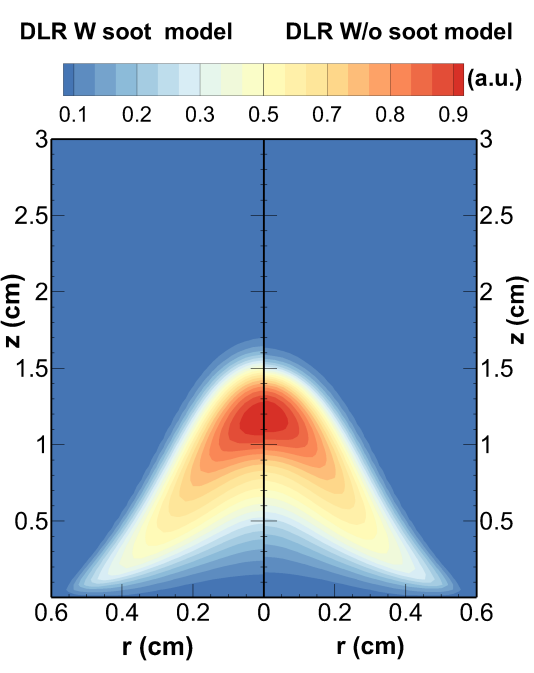

(a)

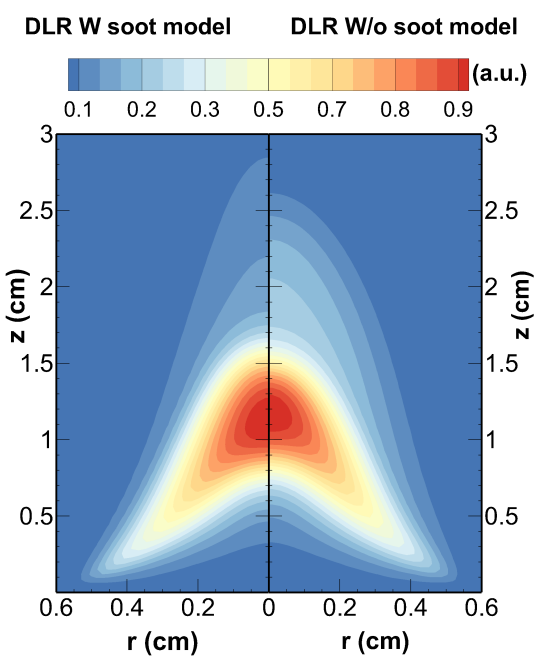

(c)

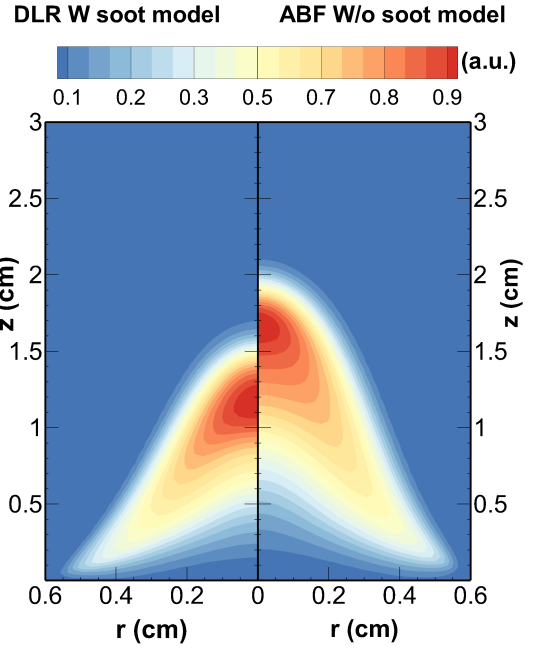

(b)

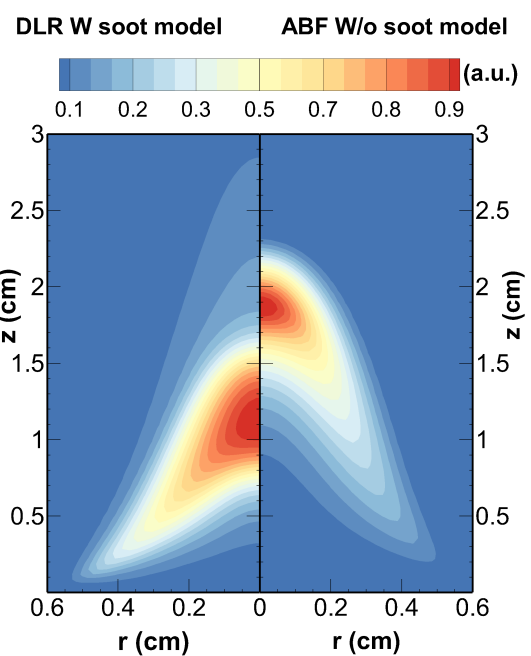

(d)

Figure 6: Comparison of computed $340 \mathrm{~nm}$ and $400 \mathrm{~nm}$ PAH fields: (a) and (c) DLR mechanism, with and without soot; (b) and (d) DLR with soot and ABF mechanisms without soot.

the DLR. Considering these results on the light of the measured soot distribution, Fig. 1 . it could be argued that coupling the ABF model to a soot model including heavier PAH would lead to moving the sooting region further downstream, and thus to a poorer agreement with the experiments. This supports the argument developed above, relating the 
$340 \mathrm{~nm}$ and $400 \mathrm{~nm}$ detection to a combination of lighter PAH. Unfortunately, due to the absence of higher molecular weight $\mathrm{PAH}$ on the ABF chemical mechanism, such an inference may not be established for the other measured wavelengths. Nevertheless, it should be emphasized that the above discussed computational results do not allow to unambiguously conclude on the validity of the used PAH gas-phase chemistry, since the direct measurement of such species is out of reach of the experimental techniques available to the authors.

\section{Conclusions}

UV-excited LII and PLIF measurements at four different detection wavelengths were compared to numerical simulation results, in order to advance the understanding of the interplay between PAH and soot formation. The experiments used a combined promptdelayed PLIF detection scheme in order to discriminate between PAH and soot signals. Soot volume fraction and temperature estimates were also confronted to numerical predictions, providing a correlation basis for the main PAH and the soot precursors. The DLR kinetic mechanism was used in this study, which should represent the state of the art and provide a PAH description until 5 ring species.

Results comparison showed that, by increasing the fluorescence signal detection wavelength, different groups of PAH can be evidenced which are characterized by an increasing number of rings at the PAH structure. Carrying out a simple summation of the different PAH mass fraction allowed for an acceptable representation of the fluorescence species observed through the LIF technique, grouping them accordingly to its molecular structure (number of rings). In particular, the performed comparisons suggest that one up to three-ringed PAH species could be detected using $340 \mathrm{~nm}$ filters, while three and four-ringed PAH could be detected using $400 \mathrm{~nm}$ filters. Larger PAH discrimination was found to be more elusive due to soot signal overlap. Furthermore, the species that were found to play a significant role at the studied wavelengths were found to be $\mathrm{AlC}_{2} \mathrm{H}, \mathrm{A} 1$, INDENE, $\mathrm{A} 3, \mathrm{C}_{18} \mathrm{H}_{12}$ and BAPHYR.

Computed soot volume fraction and temperature predictions presented a reasonable agreement, and similar trends as those observed experimentally. Computations also allowed to understand the interplay between soot production, soot radiation, and local 
temperature by increasing the fuel flow rate observed experimentally. Even though the conclusions obtained in this study are dependent on the kinetic mechanism considered (DLR), a comparison using the ABF mechanism indicates that the latter produced taller flames, in terms of the PAH distribution. In this case also lighter PAH produce lower in the flame, as observed with the DLR, but DLR produce a distribution which is more consistent with the PLIF measurements carried out. Future work is needed in order to improved and to develop more complex heavy PAH kinetic mechanism and the use of this detection technique to characterize the interplay between PAH and soot in turbulent flames.

\section{Acknowledgments}

This work was supported by Chilean CONICYT PIA/ANILLO ACT172095, FONDECYT project 1161453 and Petrobras under the technical monitoring of Dr. Ricardo Serfaty (Contract 0050.0080122.12.9). J.J. Cruz Villanueva received a PhD scholarship from CNPq and L.F. Figueira da Silva was on leave from the Institut Pprime (CNRS, France). The authors gratefully acknowledge the support for the present research provided by Conselho Nacional de Desenvolvimento Científico e Tecnológico, CNPq, under the Research Grants No. 306069/2015-6 and 403904/2016-1.

\section{References}

[1] H. Wang, Formation of nascent soot and other condensed-phase materials in flames, Proceedings of the Combustion Institute 33 (1) (2011) $41-67$.

[2] T. Bourdrel, M.-A. Bind, Y. Béjot, O. Morel, J.-F. Argacha, Cardiovascular effects of air pollution, Archives of Cardiovascular Diseases 110 (11) (2017) $634-642$.

[3] P. Desgroux, X. Mercier, K. A. Thomson, Study of the formation of soot and its precursors in flames using optical diagnostics, Proc. Combust. Inst. 34 (1) (2013) 1713 - 1738.

[4] C. Schulz, B. Kock, M. Hofmann, H. Michelsen, S. Will, B. Bougie, R. Suntz, G. Smallwood, Laser-induced incandescence: recent trends and current questions, Appl. Phys. B 83 (3) (2006) 333-354.

455 [5] R. L. V. Wal, Soot precursor material: Visualization via simultaneous lif-lii and characterization via tem, Proc. Combust. Inst. 26 (2) (1996) 2269 - 2275.

[6] R. L. V. Wal, Soot precursor carbonization: Visualization using lif and lii and comparison using bright and dark field tem, Combust. Flame 112 (4) (1998) $607-616$. 
[7] K. Siegmann, H. Hepp, K. Sattler, Reactive dimerization: A new pah growth mechanism in flames, Combustion Science and Technology 109 (1-6) (1995) 165-181. doi:10.1080/00102209508951900

[8] R. L. V. Wal, K. A. Jensen, M. Y. Choi, Simultaneous laser-induced emission of soot and polycyclic aromatic hydrocarbons within a gas-jet diffusion flame, Combust. Flame 109 (3) (1997) 399 - 414.

[9] S. Bejaoui, X. Mercier, P. Desgroux, E. Therssen, Laser induced fluorescence spectroscopy of aromatic species produced in atmospheric sooting flames using uv and visible excitation wavelengths, Combust. Flame 161 (10) (2014) 2479 - 2491.

[10] Y. Bouvier, C. Mihesan, M. Ziskind, E. Therssen, C. Focsa, J. Pauwels, P. Desgroux, Molecular species adsorbed on soot particles issued from low sooting methane and acetylene laminar flames: A laser-based experiment, Proc. Combust. Inst. 31 (1) (2007) $841-849$.

[11] K. Hayashida, K. Amagai, K. Satoh, M. Arai, Experimental Analysis of Soot Formation in Sooting Diffusion Flame by Using Laser-Induced Emissions, Journal of Engineering for Gas Turbines and Power 128 (2) (2006) 241.

[12] K. Hayashida, T. Mogi, K. Amagai, M. Arai, Growth characteristics of polycyclic aromatic hydrocarbons in dimethyl ether diffusion flame, Fuel 90 (2) (2011) 493 - 498.

[13] T. Furuhata, Y. Kobayashi, K. Hayashida, M. Arai, Behavior of pahs and pm in a diffusion flame of paraffin fuels, Fuel 91 (1) (2012) $16-25$.

[14] A. O. R. Ccacya, L. F. F. da Silva, Characterization of multi-jet turbulent flames in cross flow using stereo-piv and oh-plif, Fire Safety Journal 78 (2015) $44-54$. doi:10.1016/j.firesaf.2015.08.001

[15] N. R. Caetano, L. F. Figueira da Silva, A comparative experimental study of turbulent non premixed flames stabilized by a bluff-body burner, Exp. Therm. Fluid Sci. 63 (2015) 20-33.

[16] E. M. Orbegoso, L. F. F. da Silva, R. Serfaty, Comparative study of thermal radiation properties models in turbulent non-premixed sooting combustion, Numerical Heat Transfer, Part A: Applications 69 (2) (2016) 166-179.

[17] S. B. Dworkin, Q. Zhang, M. J. Thomson, N. A. Slavinskaya, U. Riedel, Application of an enhanced pah growth model to soot formation in a laminar coflow ethylene/air diffusion flame, Combust. Flame 158 (9) (2011) 1682-1695.

[18] A. Khosousi, S. B. Dworkin, Soot surface reactivity during surface growth and oxidation in laminar diffusion flames, Combust. Flame 162 (12) (2015) 4523-4532.

[19] M. Saffaripour, P. Zabeti, S. B. Dworkin, Q. Zhang, H. Guo, F. Liu, G. J. Smallwood, M. J. Thomson, A numerical and experimental study of a laminar sooting coflow Jet-A1 diffusion flame, Proc. Combust. Inst. 33 (1) (2011) 601-608.

[20] F. Liu, X. He, X. Ma, Q. Zhang, M. Thomson, H. Guo, G. Smallwood, S. Shuai, J. Wang, An experimental and numerical study of the effects of dimethyl ether addition to fuel on polycyclic aromatic hydrocarbon and soot formation in laminar coflow ethylene/air diffusion flames, Combust. Flame 158 (3) (2011) 547-563.

[21] A. Veshkini, S. B. Dworkin, M. J. Thomson, A soot particle surface reactivity model applied to a wide range of laminar ethylene/air flames, Combust. Flame 161 (12) (2015) 3191-3200.

[22] L. M. Verhoeven, M. H. De Andrade Oliveira, A. Lantz, B. Li, Z. S. Li, C. C. Luijten, J. A. 
Van Oijen, M. Alden, L. P. De Goey, A numerical and experimental study of Polycyclic Aromatic Hydrocarbons in a laminar diffusion flame, Proc. Combust. Inst. 34 (1) (2013) 1819-1826.

[23] V. Chernov, M. J. Thomson, S. B. Dworkin, N. A. Slavinskaya, U. Riedel, Soot formation with c 1 and c 2 fuels using an improved chemical mechanism for pah growth, Combust. Flame 161 (2) (2014) 592-601.

[24] D. R. Snelling, K. A. Thomson, G. J. Smallwood, O. L. Gülder, Two-dimensional imaging of soot volume fraction in laminar diffusion flames, Appl. Opt. 38 (12) (1999) 2478-2485.

[25] D. R. Snelling, K. A. Thomson, G. J. Smallwood, O. L. Gülder, E. J. Weckman, R. A. Fraser, Spectrally Resolved Measurement of Flame Radiation to Determine Soot Temperature and Concentration, AIAA J. 40 (9) (2002) 1789-1795.

[26] R. Hadef, K. P. Geigle, J. Zerbs, R. A. Sawchuk, D. R. Snelling, The concept of 2d gated imaging for particle sizing in a laminar diffusion flame, Appl. Phys. B 112 (3) (2013) 395-408.

510 [27] F. Escudero, A. Fuentes, J.-L. Consalvi, F. Liu, R. Demarco, Unified behavior of soot production and radiative heat transfer in ethylene, propane and butane axisymmetric laminar diffusion flames at different oxygen indices, Fuel 183 (2016) 668-679.

[28] F. Cignoli, S. Benecchi, G. Zizak, Simultaneous one-dimensional visualization of oh, polycyclic aromatic hydrocarbons, and soot in a laminar diffusion flame, Opt. Lett. 17 (4) (1992) 229-231.

[29] J. Xiao, E. Austin, W. Roberts, Relative polycyclic aromatic hydrocarbon concentrations in unsteady counterflow diffusion flames, Combust. Sci. Technol. 177 (4) (2005) 691-713.

[30] H. A. Michelsen, C. Schulz, G. J. Smallwood, S. Will, Laser-induced incandescence: Particulate diagnostics for combustion, atmospheric, and industrial applications, Prog. Energy Combust. Sci. 51 (2015) 2-48.

[31] M. Thierley, H.-H. Grotheer, M. Aigner, Z. Yang, A. Abid, B. Zhao, H. Wang, On existence of nanoparticles below the sooting threshold, Proc. Combust. Inst. 31 (1) (2007) 639 - 647. doi: https://doi.org/10.1016/j.proci.2006.08.035

[32] A. D'Anna, A. Rolando, C. Allouis, P. Minutolo, A. D'Alessio, Nano-organic carbon and soot particle measurements in a laminar ethylene diffusion flame, Proceedings of the Combustion Institute 30 (1) (2005) 1449 - 1456. doi:10.1016/j.proci.2004.08.276.

[33] H. Zhao, N. Ladommatos, Optical diagnostics for soot and temperature measurement in diesel engines, Prog. Energy Combust. Sci. 24 (3) (1998) $221-255$.

[34] H.-c. Chang, T. Charalampopoulos, Determination of the wavelength dependence of refractive indices of flame soot, Proc. R. Soc. Lond. A 430 (1880) (1990) 577-591.

530 [35] A. Fuentes, G. Legros, H. El-Rabii, J. P. Vantelon, P. Joulain, J. L. Torero, Laser-induced incandescence calibration in a three-dimensional laminar diffusion flame, Exp. Fluids 43 (6) (2007) 939-948.

[36] C. J. Dasch, One-dimensional tomography: a comparison of abel, onion-peeling, and filtered backprojection methods, Appl. Optics 31 (8) (1992) 1146-1152.

535 [37] K. J. Daun, K. A. Thomson, F. Liu, G. J. Smallwood, Deconvolution of axisymmetric flame properties using tikhonov regularization, Appl. Optics 45 (19) (2006) 4638-4646. 
[38] F. Liu, D. R. Snelling, K. Thomson, G. J. Smallwood, Sensitivity and relative error analyses of soot temperature and volume fraction determined by two-color LII, Appl. Phys. B-Lasers Opt. 96 (2009) 623-636.

[39] N. A. Eaves, Q. Zhang, F. Liu, H. Guo, S. B. Dworkin, M. J. Thomson, CoFlame: A refined and validated numerical algorithm for modeling sooting laminar coflow diffusion flames, Comput. Phys. Commun. 207 (2016) 464-477.

[40] N. A. Slavinskaya, P. Frank, A modelling study of aromatic soot precursors formation in laminar methane and ethene flames, Combust. Flame 156 (9) (2009) 1705-1722.

41] N. A. Slavinskaya, U. Riedel, S. B. Dworkin, M. J. Thomson, Detailed numerical modeling of pah formation and growth in non-premixed ethylene and ethane flames, Combustion and Flame 159 (3) (2012) 979 - 995. doi:10.1016/j.combustflame.2011.10.005

[42] J. Appel, H. Bockhorn, M. Frenklach, Kinetic modeling of soot formation with detailed chemistry and physics: laminar premixed flames of C2 hydrocarbons, Combust. Flame 121 (1) (2000) 122-136

[43] F. Liu, G. J. Smallwood, O. L. Gülder, Band lumping strategy for radiation heat transfer calculations using a narrowband model, J. Thermophys. Heat Tr. 14 (2) (2000) 278-281.

[44] Q. Zhang, H. Guo, F. Liu, G. Smallwood, M. Thomson, Modeling of soot aggregate formation and size distribution in a laminar ethylene/air coflow diffusion flame with detailed pah chemistry and an advanced sectional aerosol dynamics model, Proc. Combust. Inst. 32 (1) (2009) 761-768.

555 [45] N. A. Eaves, A. Veshkini, C. Riese, Q. Zhang, S. B. Dworkin, M. J. Thomson, A numerical study of high pressure, laminar, sooting, ethane-air coflow diffusion flames, Combust. Flame 159 (10) (2012) 3179-3190.

[46] M. Saffaripour, M. Kholghy, S. Dworkin, M. Thomson, A numerical and experimental study of soot formation in a laminar coflow diffusion flame of a jet a-1 surrogate, Proc. Combust. Inst. 34 (1) (2013) 1057-1065.

[47] P. D. Teini, D. M. Karwat, A. Atreya, Observations of nascent soot: Molecular deposition and particle morphology, Combust. Flame 158 (10) (2011) 2045-2055.

[48] M. Saffaripour, A. Veshkini, M. Kholghy, M. J. Thomson, Experimental investigation and detailed modeling of soot aggregate formation and size distribution in laminar coflow diffusion flames of jet a-1, a synthetic kerosene, and n-decane, Combust. Flame 161 (3) (2014) 848-863.

[49] A. Jerez, J.-L. Consalvi, A. Fuentes, F. Liu, R. Demarco, Soot production modeling in a laminar coflow ethylene diffusion flame at different oxygen indices using a pah-based sectional model, Fuel 231 (2018) 404-416. doi:10.1016/j.fuel.2018.05.103

[50] G. Zizak, F. Cignoli, G. Montas, S. Beneccchi, R. Dondè, Detection of aromatyc hydrocabons in the exhaust gases of a i.c. engine by laser-induced fluorescence technique, Recent Res. Devel. in Applied Spectro. 1 (1996) 17-24.

[51] M. Suto, X. Wang, J. Shan, L. Lee, Quantitative photoabsorption and fluorescence spectroscopy of benzene, naphthalene, and some derivatives at 106-295 nm, Journal of Quantitative Spectroscopy and Radiative Transfer 48 (1) (1992) 79-89.

575 [52] N. Eaves, S. Dworkin, M. Thomson, The importance of reversibility in modeling soot nucleation 
and condensation processes, Proceedings of the Combustion Institute 35 (2) (2015) 1787 - 1794.

[53] N. A. Eaves, S. B. Dworkin, M. J. Thomson, Assessing relative contributions of pahs to soot mass by reversible heterogeneous nucleation and condensation, Proceedings of the Combustion Institute 36 (1) (2017) $935-945$.

580 [54] P. Desgroux, A. Faccinetto, X. Mercier, T. Mouton, D. A. Karkar, A. E. Bakali, Comparative study of the soot formation process in a "nucleation" and a "sooting" low pressure premixed methane flame, Combustion and Flame 184 (2017) 153 - 166. doi:10.1016/j.combustflame.2017.05.034

[55] M. R. Kholghy, A. Veshkini, M. J. Thomson, The core-shell internal nanostructure of soot - a criterion to model soot maturity, Carbon 100 (2016) $508-536$. 